\title{
A DIÁSPORA AFRICANA NA AMÉRICA LATINA, TOLERÂNCIA OPRESSIVA E PERSPECTIVAS DE TRANSFORMAÇÃO
}

\author{
Dennis de Oliveira
}

\begin{abstract}
Doutor em Ciências da Comunicação (ECA/USP), diretor do Centro de Estudos Latino-Americano sobre Cultura e Comunicação (CELACC) e Professor-titular do Departamento de Jornalismo e Editoração da ECA/USP.
\end{abstract}

\section{Resumo}

A violência étnico-racial é o elemento fundante do modelo de relações sócio-políticas na América Latina. Diante disto, os mecanismos de poder e resistência se expressam em uma práxis de caráter racial, constituindo arquétipos como o mestiço que, de forma ambivalente, tanto servem para os projetos de subjugação política como determinados projetos de afirmação nacional. É no campo dos embates étnico-raciais que também surgem as possibilidades de subjetividades políticas alternativas no continente.

Palavras-chave: racismo e política; anti-racismo e transformação; racismo e mestiçagem; racismo e tolerância opressiva

\section{Abstract}

The ethnic-racial violence is the most important element of the model of socio-political relations in Latin America. Then, the mechanisms of power and resistance are expressed in a praxis of racial character, being archetypes as the mestizo who, in an ambivalent way, both to serve the designs of political subjugation and certain projects of national affirmation. It is in the field of racial-ethnic clashes also emerging possibilities of subjectivities alternative policies on the continent.

Keywords: racism and politics; anti-racism and transformation; racism and miscegenation; racism and oppressive tolerance

\section{Resúmen}

La violencia étnica-racial es el elemento más importante del modelo de las relaciones socio-políticas en América Latina. Teniendo en cuenta esto, los mecanismos de poder y resistencia se expresa en una praxis de carácter racial, los arquetipos ser como el mestizo que, de manera ambivalente, tanto para servir a los designios de sometimiento político cómo algunos proyectos de afirmación nacional. Es en el campo de los enfrentamientos étnico-racial también nuevas posibilidades para las subjetividades políticas alternativas en el continente.

Palabras clave: racismo y la política; lucha contra el racismo y la transformación; racismo y mestizaje; racismo y la tolerancia opresiva 


\section{Introdução}

A América Latina é produto de processos de violência. Violência perpetrada pela colonização, pelo histórico de governos despóticos, pelo tratamento aos movimentos sociais, pela desigualdade social, pelo lugar subalterno na economia mundial e pelas violências étnicas.

\section{Aníbal Quijano afirma que}

\footnotetext{
"a produção histórica da América Latina começa com a destruição de todo um mundo histórico, provavelmente a maior destruição sociocultural e demográfica da história que chegou ao nosso conhecimento." (2005: p.16)
}

Quijano refere-se a destruição das civilizações dos povos originários das Américas porém agregamos a isto a destruição também das civilizações africanas com o advento da transplantação forçada e da escravização dos povos daquele continente.

O processo de violência que constitui o que conhecemos hoje como América Latina desenvolve-se por meio de quatro mecanismos: a) desintegração dos padrões de poder e de civilização de experiências avançadas da humanidade, como as dos povos originários e africanos; b) genocídio físico destas populações; c) eliminação deliberada dos mais importantes líderes destas experiências; d) estabelecimento de formas de repressão material e continuada dos sobreviventes de maneira a impedir a constituição de subjetividades alternativas. (Quijano, 2005)

Diante disto, os conflitos étnicos se transformaram no motor principal da dialética poder/resistência nestas sociedades e a arena política passa a ser contaminada pelas dinâmicas de negociação e conflito de demandas sócio-culturais.

Esta dinâmica recrudesce mais nos momentos recentes quando emerge categorias novas para a dimensão política não associadas diretamente às categorias clássicas do contrato social liberal. Segundo Martin Hopenhayn,

\footnotetext{
"a cidadania se enfrenta cada vez mais com a questão da afirmação da diferença e promoção da diversidade. Campos de auto-afirmação cultural que antes eram de competência exclusiva das negociações privadas e auto-referências dos sujeitos coletivos, hoje passam a ser da competência da sociedade civil, da conversação dirigida para fora e do devir político e devir público das reivindicações associadas." (2002: p.7)
}

Esta mudança do terreno da cidadania ocorre em um momento de nova reconfiguração do capitalismo em escala global, na qual há uma nítida redução do espaço do trabalho como locus de expressão pública das classes subalternizadas. $\mathrm{O}$ novo modelo de produção e consumo capitalista prescinde do trabalho - dados apresentados pelo pensador Manuel Castells apontam que entre 1970 e 1992 a economia 
japonesa cresceu $173 \%$ e o emprego apenas $25 \%$, situação semelhante a alguns países da América Latina em que não há uma correspondência direta entre o crescimento econômico e o aumento de oportunidades de trabalho.

Para Quijano, a experiência histórica da América Latina produz um novo padrão de poder baseado na eleição da categoria raça e etnia como mecanismos legitimadores das assimetrias sociais. O impacto ideológico do racismo como ideologia estruturante do poder reside no fato dela naturalizar as relações sociais assimétricas ("a ideia de que os dominados são o que são não como vítimas de um conflito de poder mas sim enquanto inferiores em sua natureza material e, por isto,em sua capacidade de produção histórico-cultural” (p. 17)) colocando como práticas de exercício do poder mecanismos de destruição das subjetividades constituídas dentro dos marcos destas experiências culturais.

Assim, a dinâmica poder/resistência originalmente colocada dentro da perspectiva etno-cultural como mecanismo de intensificação da exploração do trabalho (seja ele no modelo escravagista ou no assalariamento capitalista) atualmente emerge como um conflito que coloca para os Estados nacionais latino-americanos o desafio de constituição de contratos sociais que abarquem as múltiplas possibilidades de subjetividades e afirmação das diferenças.

Estas são as premissas teóricas em que abordaremos a problemática dos afrodescendentes na América Latina e as perspectivas dos movimentos sociais negros no combate ao racismo no continente.

\section{Afrodescendentes na América Latina}

$\mathrm{O}$ contingente de afrodescendentes no continente latino-americano representa em torno de $30 \%$ da população total, o que significa próximo a 120 milhões de pessoas. Os dados não são precisos pois em alguns países do continente, a população afrodescendente é mínima e não se dispõe de dados atualizados.

Quase $65 \%$ do total de afro-latino-americanos se encontram no Brasil, considerado o país com maior população negra fora da África e cuja colonização e formação do capital primitivo foi feito com base na exploração da escravização de africanos.

O pesquisador Luís Ferreira, no Núcleo de Estudos Afro-brasileiros da UnB (Universidade de Brasília) divide a participação de afrodescendentes nos países latino-americanos e Caribe em quatro faixas:

a) participação acima de $85 \%$ do total da população em treze países do Caribe (Jamaica, Saint Kitts e Nevis, Dominica, Santa Lucia, Haiti, Granada, Guada- 
lupe, Barbados, Antiqua e Barbuda, S. Vicente, Bahamas, República Dominicana).

b) participação de $41 \%$ a $66 \%$ - Guiana Francesa, Trinidad e Tobago, Guiana, Suriname, Cuba e Brasil.

c) participação de 9 a 31\% - Colômbia, Panamá, Venezuela, Equador, Nicarágua, Uruguai e Belize.

d) participação menor que 5\% - Peru, Honduras, Costa Rica, Bolívia, Argentina, México, Guatemala, El Salvador, Paraguai e Chile.

O conceito que unifica este imenso contingente de afrodescendentes na América Latina é sua origem de transplantação forçada. Por isto, para Paul Gilroy (2002), as identidades negras da diáspora se constroem não apenas a partir da memória do trauma original da escravidão e da vivência posterior da violência racial, mas também a partir de experiências radicais de desenraizamento e metamorfoses culturais.

Esta experiência diaspórica afro-latino-americana se expressa em várias experiências de resistência política, das quais destacamos as reconstruções espaço-sócio-políticas dos quilombos e dos projetos revolucionários como o que emancipou o Haiti em 1804 e as reconstruções cosmológicas que reconectaram com as tradições de matriz africana (principalmente as experiências do candomblé ketu no Brasil e a santeria lucumi em Cuba) e as ressemantizações de complexos religiosos europeus ou dos povos originários (protagonizados principalmente pelos africanos de origem bantu) chamados, imprecisamente por alguns estudiosos, de sincretismo religioso.

A transposição forçada de africanos para a América Latina e Caribe foi uma empresa lucrativa que gerou recursos suficientes para a Europa ocidental realizar a sua Revolução Industrial. Eric Williams atesta que a Inglaterra, como centro financiador e hegemônico da empresa escravista, auferiu recursos suficientes para sair na frente na revolução industrial que começa a por fim ao modelo escravagista na América.

Entretanto, o novo modelo que emergia consolidava-se na supremacia dos antigos proprietários da empresa escravista e, embora o mecanismo de opressão baseado na escravização de africanos se mostrava perto do fim, o racismo, como mecanismo legitimador do mesmo, não - ele apenas se transfigurava para uma estrutura de universalização de um modelo de sociabilidade desenvolvido no contexto particular das sociedades europeias.

Desta forma, colocava-se para as elites dirigentes da América Latina ou a perspectiva de branqueamento e afastamento por completo das perspectivas de subjetividades apresentadas pelas etnias subalternizadas - o que implicaria em uma admissão de subalternidade na geopolítica mundial, ser sócio minoritário no poder global - ou 
a construção de projetos políticos alternativos cujo epicentro fosse a afirmação da diferença e afastamento da perspectiva eurocêntrica.

A mestiçagem surge como denominador comum destas duas perspectivas. À direita, aparece como um elemento atenuante de um mal estar, uma redução de um complexo de inferioridade das elites por viver em um país não branco. À esquerda, a mestiçagem atua como uma categoria de afirmação de uma singularidade nacional que legitima um projeto nacional e de contraposição ao imperialismo. É por isto que tanto a direita como a esquerda encontram dificuldades de discutir o problema das relações étnico-raciais e sempre recorrem ao arquétipo do mestiço para reduzir o impacto do problema.

\section{Poder, mestiçagem e racismo}

A política de branqueamento levada a cabo principalmente em países com grande contingente de população afrodescendente e com perspectivas de participar com maior destaque no jogo do poder global transfigurou as tradições de matriz africana para o quesito cor. Diante disto, propostas racistas como a eugenia - baseada em uma falsa suposição de diferenças biológicas e natas entre "raças" e que pregava a apartação entre os diferentes - foram transfiguradas em países como o Brasil e a Venezuela em branqueamento, o incentivo à mestiçagem como forma de apagar a visibilidade que a presença africana trazia a paisagem sócio-cultural destes países.

Com isto, há uma reprodução simbólica de valorização do "mestiço" como um elemento que particulariza a realidade latino-americana e serve como suporte para projetos nacionalistas que emergem, particularmente, no início do século XX e principalmente durante o período das guerras mundiais que selaram a decadência da Europa como centro do capitalismo global.

O elemento do "mestiço" serviu para incorporar determinados valores das subjetividades de matriz africana e indígena dissociando-as das suas origens e, principalmente, destituindo-as do contexto de violência em que foram produzidas. Não se pode esquecer que as relações sexuais entre brancos colonizadores e africanos escravizados davam-se dentro de um contexto de violência escravagista e suportados ideologicamente pela caracterização de desumanização (principalmente pelo fato dos africanos não serem oriundos da tradição cristã). A ideologia centrada no mestiço tanto serviu para apresentar uma particularidade que sustentava a reivindicação de um lugar diferenciado para os Estados nacionais latino-americanos como também para mascarar as violências raciais que ocorreram internamente nestas nações.

Além disto, a ideia de cor foi um parâmetro importante para resolver a equação embranqueamento $=$ ascensão social, imposta como mecanismo de mobilidade social em 
uma sociedade marcada por estruturas de poder constituídas com base no racismo. $\mathrm{O}$ congelamento patrimonialista que praticamente impede processos de mobilidade social ou mesmo incorporação de amplos segmentos sociais ao sistema de consumo, a dificuldade de se estruturar Estados de bem estar social por desinteresse de elites que se contentam em ser gerenciadoras de mecanismos de produção de bens destinados ao centro do capitalismo coloca no clareamento - articulado com a perspectiva de uma tolerância nas relações pessoais - um lugar de ascensão negado cotidianamente em outros espaços.

Uma pesquisa realizada pelo cientista político Alberto Almeida (2006) detectou que a maioria dos brasileiros demonstra mais preconceito contra os pardos (mestiços) que os que têm a pele mais escura (pretos). Para ele,

\footnotetext{
"o preto é visto muitas vezes como alguém que não teve chance na vida mas que conhece seu lugar. Já o pardo pode ser visto como alguém que teima em disputar posições com os brancos".
}

Talvez a conclusão mais precisa de estes dados é que existe um processo de exclusão racial que atinge prioritariamente os mais escuros (portanto, os que não têm a chance a vida e que devem conhecer o seu lugar, o seu batustão) reduzindo a medida que se vai clareando a pele (branqueamento $=$ possibilidades maiores de mobilidade social) e um incômodo maior (preconceito) quando estes afrodescentendes "clareados" aproximam-se do espaço branco, buscando disputar posições.

Por esta razão, podemos caracterizar as relações étnicas na América Latina como de tolerância opressiva, isto é, a tolerância de existência do outro articula-se com as possibilidades de opressão continua para que se legitime e se possa exercer o poder em suas múltiplas dimensões. Em outras palavras, admite-se a existência do diferente desde que este não se atreva a disputar ou questionar os privilégios obtidos por uma hierarquia racial construída.

\section{O mito de Tântalo como metáfora da "pós-modernidade latino-americana"}

O problema das relações étnicas na América Latina se exacerba com a emergência de dois processos do capitalismo contemporâneo:

a) a queda do espaço do trabalho como possibilidade de ação pública, em função das novas configurações da produção capitalista que prescinde de uma grande massa de trabalhadores empregados, gerando uma grande camada de desemprego estrutural e acirrando as disputas pelos poucos postos de trabalho;

b) as possibilidades muito maiores de acesso à informação, gerando o que muitos pensadores chamam de "sociedade da informação", em que um sem número 
de símbolos, produtos, situações codificadas principalmente de forma imagética circulam de forma evanescente por todo o planeta.

A centralidade midiática descentra o indivíduo, pondo fim a ideia de uma universalidade e autocentramento no ser humano, típicas do projeto moderno europeu. O denominador comum deste indivíduo autocentrado - o trabalho - também perde espaço simbólico, gerando um desejo de consumo sem a contrapartida. Estes processos são de ordem global mas têm impactos diferentes e mais catastróficos em sociedades marcadas pelas assimetrias e violência étnica como as latino-americanas. Nestas sociedades, o trabalho sempre foi associado a uma dimensão de menoridade, de inferioridade, devido a herança escravista, e quando foi estabelecido o sistema de assalariamento aconteceu dentro de dinâmicas de super-exploração da mão de obra utilizando o racismo como ferramenta ideológica de legitimação.

Mesmo assim, para as classes subalternizadas, o trabalho apresentava-se como uma possibilidade de visibilidade pública restrita, de acesso a alguns mecanismos de exercício da cidadania, particularmente após a normatização das relações trabalhistas. Mas o modelo de capitalismo de fornecedor de matérias primas e produtos semimanufaturados para os países centrais prescindiu de políticas de inclusão social e mesmo de um Estado de bem estar social. Desta forma, o capitalismo latino-americano sempre conviveu com formas arcaicas de superexploração da mão de obra bem como um altíssimo e permanente contingente de desempregados, criando uma escala valorativa no trabalho - do trabalho precário ao trabalho normatizado e, dentro deste, do trabalho manual e intelectual - articulada com as dimensões raciais (o branqueamento implicaria também em possibilidades de mobilidade nesta escala do trabalho, a ponto de funções laborais com mais visibilidade pública são destinadas aos mais "claros" e as mais invisíveis, aos mais "escuros"). Branquear, aqui, significa ampliar oportunidades de ascensão na escala laboral.

Com o advento do modelo neoliberal, há um aumento vertiginoso do espaço do trabalho precário (a precarização do trabalho é uma consequência direta do novo modelo de acumulação capitalista) e uma redução do espaço do trabalho melhor remunerado e mais normatizado, acirrando ainda mais os critérios raciais para a mobilidade nesta escala.

Este acirramento das práticas racistas como mecanismos selecionadores em uma dimensão laboral cada vez mais restritiva é acompanhada por uma maior visibilidade de diferenças de subjetividade perpetrada pela indústria da mídia. $\mathrm{O}$ acesso maior a informações, bem como a busca incessante da indústria midiática por novos produtos para atender demandas novas e crescentes a faz buscar em elementos culturais até então marginalizados fontes para a construção de novas imagens. Assim, as classes subalternas conseguem ter acesso a um espetáculo que fingem participar mas 
são excluídas do processo. O limite imposto por este novo modelo societário é o de vê sem usufruir.

Utilizaremos o mito grego de Tântalo para exemplificar isto. Na mitologia grega, Tântalo foi um homem que, em certo momento, roubou um segredo que era exclusivo aos deuses e o disseminou junto aos mortais. O castigo imposto pelos deuses do Olimpo foi amarrá-lo em um lago, com uma árvore frutífera acima de sua cabeça e água até os seus peitos. Quando Tântalo sentia sede, a água abaixava para fora do seu alcance. O mesmo acontecia quando Tântalo sentia fome e tentava apanhar as frutas, que voavam para longe do alcance da sua boca. Assim, a agonia desta figura mítica era ficar constantemente olhando aquilo que saciaria o seu desejo mas sem poder satisfazê-lo.

A agonia de Tântalo é a metáfora do mundo de hoje. O acesso à informação ocorre em uma velocidade muito mais rápida que o acesso aos bens e riquezas. Estatísticas da CEPAL (Comissão Econômica para América Latina) demonstram que entre 1980 e 1990 o consumo privado por habitante na América Latina cresceu 1,7\%, neste mesmo período a Unesco calcula que o número de televisores para cada grupo de 1.000 habitantes cresceu $95,91 \%$, sem contar o crescimento das horas de programação. Assim, ao mesmo tempo em que se radicaliza e estrutura um processo de exclusão social, há uma inclusão em um mundo virtual de consumo, onde desejos são potencializados, mas nunca realizados, na mesma perspectiva da agonia de Tântalo.

Marilena Chauí (2006) ao analisar este fenômeno chama a atenção para uma destruição da esfera pública - enquanto espaço de realização da discussão política - e a incorporação da sociedade em um mundo virtual de consumismo, gerando o que ela chama de uma infantilização das ações sociais. Infantilização é utilizada por Chauí a partir da referência freudiana de considerar infantil a não compreensão da diferença entre o desejo e a realização do desejo - isto é, o trabalho (enquanto investimento de uma ação humana) como trajetória para isto. Disto, resulta a emergência de comportamentos violentos e de desagregação social que tornam-se o principal cenário das sociedades latino-americanas.

Para Hopenhayn,

"Exemplo claro dessa situação constituem os jovens populares urbanos, uma população com mais educação e conhecimento, mais expectativas de consumo pela sua exposição à indústria cultural, que tem internalizado com mais força as promessas de desenvolvimento que emanam do discurso dos políticos e dos economistas, mas 
que, por outro lado, duplica em desemprego com relação ao resto da população." (2002: p. 16)

\section{Subjetividades e busca de protagonismos: a reconstrução de uma nova arena política}

O cenário de crise e de violência exacerbada na América Latina é também uma possibilidade de criação de uma nova forma de exercício da política que já vem sendo timidamente experimentada a medida que surgem, particularmente no final do século XX e início do XXI, movimentos de reivindicação de identidades culturais e também de exigência de novos protagonismos e empoderamentos.

As recentes experiências de democratização das sociedades latino-americanas possibilitaram a inclusão de demandas étnicas reprimidas, questionando o fator étnico como mecanismo de assimetrias sociais. Assim, a luta anti-racista na América Latina confunde-se com buscas de repactuação do contrato social, uma vez que este foi constituído a partir de uma exclusão de determinados grupos étnicos, entre eles os afrodescendentes.

Por isto, a perspectiva para a América Latina é o fortalecimento das demandas de ordem identitária e o enfrentamento disto dá-se pelo reconhecimento dos processos violentos que se construiu o continente e a busca de novos modelos de sociabilidade que levem em conta a pluralidade de subjetividades, a partir da criação de mecanismos institucionais em que a visão da diversidade seja o epicentro da construção de um novo contrato social. É nesta perspectiva que se insere a necessidade de políticas de ação afirmativa que não apenas propiciem novas oportunidades e possibilidades para os jovens afrodescendentes e indígenas, mas também contribuem para que espaços, até então totalmente hegemonizados por "brancos" se pluralizem, quebrando os bantustões simbólicos que articulam a dimensão da cor a uma escala de possibilidades e valores.

É evidente que este processo necessita ser acompanhado pela geração maior de oportunidades e uma revisão do papel da indústria da mídia e da educação como mecanismos de formação das consciências. 
Referências bibliográficas

ALMEIDA, Alberto. A cabeça do brasileiro. Rio de Janeiro: Record, 2006 CHAUÍ, Marilena. Simulacro e poder: uma análise da mídia. São Paulo: Perseu Abramo, 2006

FERREIRA, Luiz. A diáspora africana na América Latina e no Caribe in: Diálogo interamericano, São Paulo: USP, 2002

GILROY, Paul. O Atlântico negro - Modernidade e dupla consciência. Rio de Janeiro: Editora 34/UCAM, 2002

HOPENHAYN, Martin. A cidadania vulnerabilizada na América Latina in: Revista Brasileira de Estudos da População, v. 19, n.2 - jul/dez 2002

LEON, Irene. Por um milenio plural y diverso. Quito: Alai, 2001

PATEMAN, Carole; MILLS, Charles. Contract \& Domination. Cambridge: Polity Press, 2007

QUIJANO, Anibal. Dom Quixote e os moinhos de vento na América Latina in: Revista do Instituto de Estudos Avançados (IEA), v. 19, n. 55, São Paulo: USP, 2005 